\title{
Mass Spectra of Some Lead Alkyls
}

\author{
Edith I. Quinn, Vernon H. Dibeler, and Fred L. Mohler
}

\begin{abstract}
Monoisotopic mass spectra are given for the compounds: tetramethyllead, trimethylethyllead, dimethyldiethyllead, methyltriethyllead, tetraethyllead, tetrapropyllead, trimethyl-n-butyllead, trimethyl-sec-butyllead, trimethyl-tert-butyllead, and tetra-isobutyllead. Relations between relative probabilities of ion formation and molecular structure are observed for several ion configurations and are discussed briefly.
\end{abstract}

\section{Introduction}

The systematic comparison of the mass spectra of a group of related compounds not only affords a basis for chemical analysis but also provides information on the molecular structure and relative probabilities of bond dissociation processes. Organometallic compounds are particularly interesting for this purpose, and studies of mass spectra have been reported for a number of these, including the tetramethyl compounds of the group IV elements $[1],{ }^{1}$ lead and mercury alkyls [2], and the cyclopentadienyl compounds of $\mathrm{V}, \mathrm{Cr}, \mathrm{Fe}, \mathrm{Co}, \mathrm{Ni}, \mathrm{Re}, \mathrm{Ru}, \mathrm{Mn}$, and $\mathrm{Mg}$ [3].

The concomitant data of isotope abundance ratios obtained for the metallic elements in organometallic compounds is also of interest. Although possible interference from ions formed by rearrangement during the ionization-dissociation process (e. g., hydride ions) preclude their use for discovering rare isotopes, satisfactory agreement has been obtained in the comparison of routine analyses of lead, using the halides and the tetramethyl compound [4], and of mercury, using the element and the dimethyl compound [5].

The present study, made possible through a gift of the lead alkyls from the Ethyl Corp., Detroit, extends the published mass spectral data of lead alkyls to include trimethylethyllead, dimethyldiethyllead, methyltriethyllead, tetra- $n$-propyllead, trimethyl- $n$-butyllead, trimethyl-sec-butyllead, trimethyl-tert-butyllead, and tetra-iso-butyllead. Relative dissociation probabilities are compared for the several molecules and conclusions noted with regard to molecular structure and mass spectra.

\section{Experimental Details}

Mass spectra were obtained by using a Consolidated 21-103 mass spectrometer and conventional procedures. In preliminary experiments, liquid samples were introduced through a gallium-covered porous glass frit [6]. However, considerable holdup was observed for the heavier liquids, and as a result the sample pressure did not reach a steady value and pump-out time was excessive. The use of a mercurysealed orifice [7] avoids these difficulties. There was no indication of reaction between the mercury and the lead alkyls.

\footnotetext{
1. Figures in brackets indicate the literature references at the end of his paper.
}

A resolving power of about 1 in 500 was obtained by reducing the width of the collector slit from 32 to 6 mils and by the use of a high potential on the "metastable suppressor." This electrode is located between the collector slit and the collector, and in addition to filtering out ions that have lost energy through metastable transitions, it also acts as a virtual limiting slit.

Table 1 lists the lead alkyls and the purities as stated by the supplier. The tetramethyllead and tetraethyllead were part of the same samples used in a previous study [2]. Recognized impurities in the samples were principally alkyl halides, except in the case of the trimethyl-tert-butyllead, which contained tert-butanol in excess of the total reported impurity and may have resulted from some decomposition of the sample. Mass spectral contributions of these impurities were subtracted from the lead alkyl spectra. Impurities consisting of other organo-lead compounds are not easily identified. One check on the purity is to compare the spectrum of the vapor in contact with an excess of liquid with the spectrum obtained when a small sample of liquid is completely vaporized. In the first spectrum, lower vaporpressure impurities are suppressed whereas those with higher vapor pressures are enhanced. This technique disclosed approximately 0.1 percent of trimethylethyllead and dimethyldiethyllead in the tetramethyllead sample.

TABLE 1. Purity of lead alkyls as reported by the supplier

\begin{tabular}{|c|c|c|}
\hline Compound & Formula & Purity \\
\hline Trimethylethyllead & $\left(\mathrm{CH}_{3}\right)_{3} \mathrm{PbC}_{2} \mathrm{H}$ & $99^{+}$ \\
\hline Dimethyldiethyllead. & $\left(\mathrm{CH}_{3}\right)_{2} \mathrm{~Pb}\left(\mathrm{C}_{2} \mathrm{H}_{5}\right)_{2}$ & 99 \\
\hline Methyltriethyllead. & $\mathrm{CH}_{3} \mathrm{~Pb}\left(\mathrm{C}_{2} \mathrm{H}_{5}\right)_{3-}$ & $99^{4}$ \\
\hline Tetra- $n$-propyllead & $\left(n-\mathrm{C}_{3} \mathrm{H}_{7}\right)_{4} \mathrm{~Pb}$ & 95 \\
\hline Trimethyl- $n$-butlyllead & $\left(\mathrm{CH}_{3}\right)_{3} \mathrm{~Pb}\left(n-\mathrm{C}_{4} \mathrm{H}_{9}\right)$ & 95 \\
\hline Trimethyl-sec-butyllead - & $\left(\mathrm{CH}_{3}\right)_{3} \mathrm{~Pb}\left(\mathrm{sec}-\mathrm{C}_{4} \mathrm{H}_{8}\right)$ & 95 \\
\hline $\begin{array}{l}\text { Trimethy-tert-butylle } \\
\text { Tetra-iso-butyllead.. }\end{array}$ & $\left(i-\mathrm{C}_{3}\right)_{3} \mathrm{~Pb}$ (tert $\left.-\mathrm{C}_{4} \mathrm{H}_{9}\right)$ & 99 \\
\hline
\end{tabular}

The relative abundance of lead isotopes in natural ores is subject to large variations. "Common lead," which is frequently a mixture from several sources, may also exhibit variations. In this research, the isotope ratios are computed independently for each compound. However, as the preparation of the samples dates to 1934 and the 
origin of the leads is unknown, small variations in the isotope ratio observed in these samples, although probably real, are not a matter of scientific interest.

\section{Results}

The polyisotopic spectra of the lead alkyls have been submitted for publication elsewhere [8]. As dissociation processes are difficult to interpret from mass spectra of molecules containing elements with a number of isotopes of comparable abundance, monoisotopic spectra are computed. First, contributions of ions containing $\mathrm{C}^{13}$ and $\mathrm{D}$ are subtracted in the conventional manner by using a $\mathrm{C}^{12} / \mathrm{C}^{13}$ ratio of 91.0 and an H/D ratio of 6700 . Common lead is composed of four isotopes with the approximate percentage abundances: $204: 206: 207: 208=1.3: 26: 21: 52$. Thus each ion of formula $\mathrm{Pb}(\mathrm{R})_{n}$ gives rise to four mass peaks in addition to the peaks resulting from ions containing $\mathrm{C}^{13}$ and D atoms. A method for obtaining the isotope abundance ratios and applying them to the computation of the monoisotopic spectra has been described in detail $[1,2]$.

Table 2 summarizes the principal ions in the $70-\mathrm{v}$ monoisotopic spectra of 10 lead alkyls, including tetramethyl and tetraethyllead. The abundances are relative to the most abundant ion taken as 100 . Observed molecule ions are in boldfaced type. The sensitivities (ion current per unit of pressure in the sample reservoir) of the most abundant ions are expressed as relative to the sensitivity of the $\mathrm{C}_{3} \mathrm{H}_{7}^{+}$ ion of $n$-butane. These appear in the last line of the table.

\section{Discussion}

The hydrocarbon ions in general, and particularly the methyl ions in the lead alkyl mass spectra, may exhibit variations in relative abundance for instrumental reasons, and conclusions based thereon are subject to some uncertainty. Nevertheless, some interesting results are observed. The relative abundance of the $\mathrm{CH}_{3}^{+}$ions in tetramethyllead, the methylethylleads, and tetraethyllead consistently decreases with the number of $\mathrm{Pb}-\mathrm{CH}_{3}$ linkages. In the methylbutylleads the $\mathrm{CH}_{3}^{+}$abundance is affected by the configuration of the butyl radical as a low $\mathrm{CH}_{3}^{+}$abundance occurs for the $n$-butyl, whereas a high abundance is observed for the tertiary butyl compound.

The abundance of $\mathrm{C}_{2} \mathrm{H}_{5}+$ ions also follows a logical relation to molecular structure, except in the case of tetraethyllead. Formation of the $\mathrm{C}_{2} \mathrm{H}_{5}{ }^{+}$ion by dissociation of the $\mathrm{Pb}-\mathrm{C}_{2} \mathrm{H}_{5}$ linkage is relatively less probable than formation of $\mathrm{CH}_{3}{ }^{+}$from $\mathrm{Pb}\left(\mathrm{CH}_{3}\right)_{4}$.

The relation of abundance of propyl and butyl ions to molecular structure is evidently complicated. The formation of $\mathrm{C}_{3} \mathrm{H}_{7}+$ ions is relatively improbable in the tetrapropyl compound, and analogous to the tetraethyllead. The increased abundance in the trimethyl-tert-butyllead is unexpected because of the complicated dissociation process involved and the low abundance in the tetra-iso-butyllead. The abundance of the $\mathrm{C}_{4} \mathrm{H}_{9}{ }^{+}$ion in the sec-butyl compound is not consistent with the order of bond energies: primary $>$ secondary $>$ tertiary.

TABLE 2. Principal ions in the monoisotopic spectra of some lead alkyls a

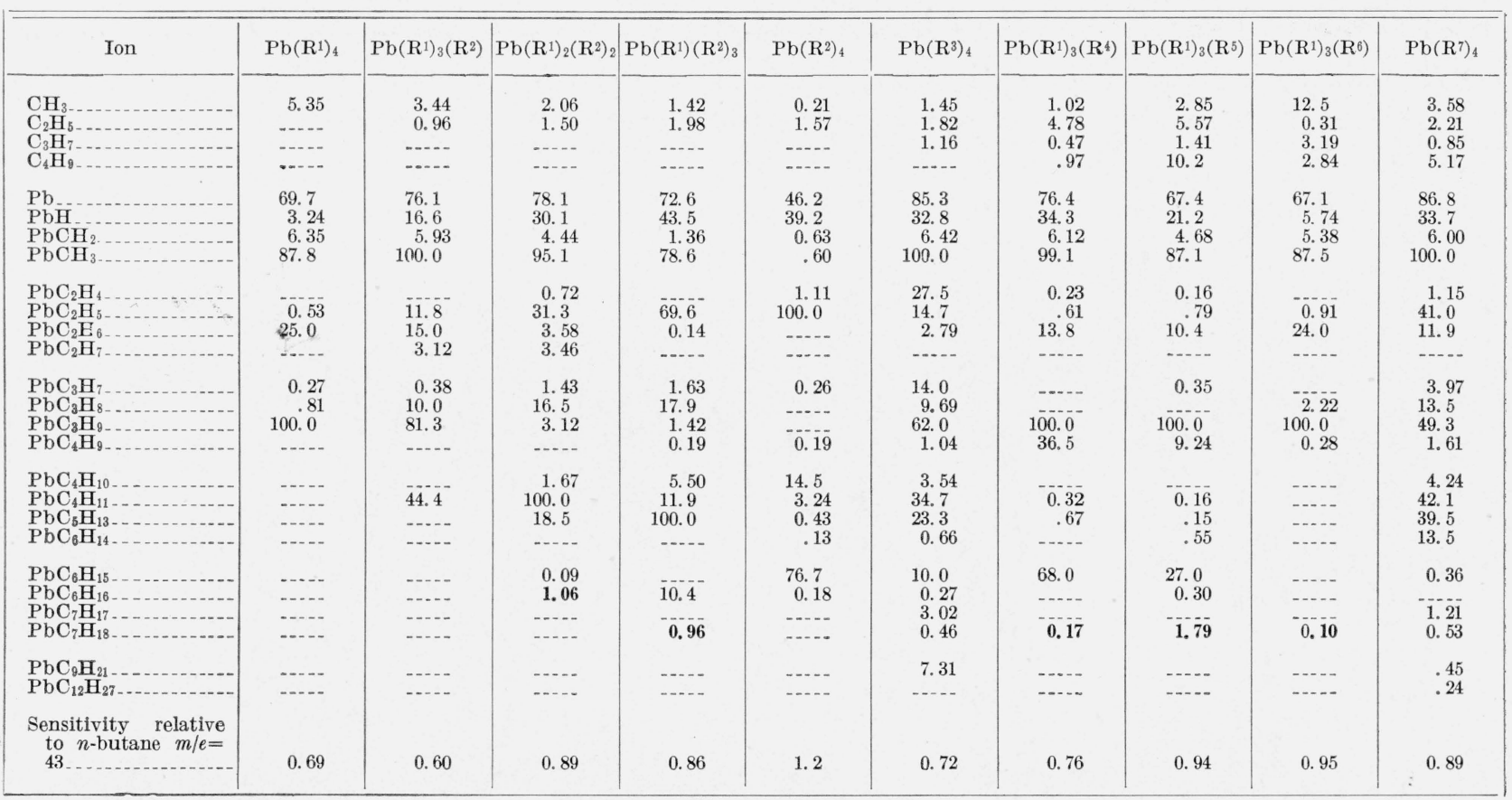

s $\mathrm{R}^{1}=\mathrm{CH}_{3}, \mathrm{R}^{2}=\mathrm{C}_{2} \mathrm{H}_{5}, \mathrm{R}^{3}=\mathrm{C}_{3} \mathrm{H}_{7}, \mathrm{R}^{4}=n-\mathrm{C}_{4} \mathrm{H}_{9}, \mathrm{R}^{5}=s-\mathrm{C}_{4} \mathrm{H}_{9}, \mathrm{R}^{6}=t-\mathrm{C}_{4} \mathrm{H}_{9}, \mathrm{R}^{7}=i s 0-\mathrm{C}_{4} \mathrm{H}_{9}$. 
Hydrocarbon 1ons apparently resulting from rearrangement during ionization-dissociation processes have been noted previously for tetramethyllead [1] Traces of impurities in the compounds used in this research effectively masked such ions and prevent further discussion concerning their origin.

Lead atom ions are of comparable abundance in all of the compounds. The abundance of $\mathrm{PbH}^{+}$ions, although comparable for most of the compounds, is relatively low in the tetramethyllead and the trimethyl-tert-butyllead.

The $\mathrm{PbCH}_{3}{ }^{+}$ion is one of the principal ions in all of the lead alkyl spectra except tetraethyllead. Although the latter requires rearrangement to form the monomethyllead ion, the tetrapropyllead and tetra-iso-butylleads also require rearrangement, and the $\mathrm{PbCH}_{3}{ }^{+}$ion is the most abundant ion in the spectra of these compounds.

The abundances of the $\mathrm{PbC}_{2} \mathrm{H}_{5}+$ ion are generally consistent with the structure of the lead alkyls, e. g., the abundance increases with substitution of ethyl radicals for methyl groups of tetramethyllead. The low abundance of this ion in the methylbutyl compounds is consistent with structure. However, the tetrapropyllead and tetra-iso-butyllead compounds are exceptions. Formation of this ion by dissociation of a hydrogen atom from a dimethyllead configuration evidently occurs with low probability.

The abundances of the dimethyllead ion, $\mathrm{PbC}_{2} \mathrm{H}_{6}^{+}$, are also generally consistent with molecular structure. Increased substitution of ethyl radicals for methyl radicals in the methyl-ethyl leads results in decreased abundance. Formation of this ion in tetrapropyllead and the butyl leads is by rearrangement. The $\mathrm{PbC}_{2} \mathrm{H}_{7}+$ ions are evidently hydrides of the dimethyllead ion formed by rearrangement.

As expected, the trimethyllead ion, $\mathrm{PbC}_{3} \mathrm{H}_{9}{ }^{+}$, is abundant for molecules having 3 or 4 methyl groups. The relatively large abundance of this ion observed in the tetrapropyllead and tetra-iso-butyllead spectra suggests a dihydride of the monopropyllead $\mathrm{H}_{2} \mathrm{PbC}_{3} \mathrm{H}_{7}{ }^{+}$. This is suggested by the apparent high stability of the ion configuration, $\mathrm{PbR}_{3}{ }^{+}$, in which three bonding orbitals of the central lead atom are occupied by hydrogen atoms or alkyl groups. Such stability is demonstrated by the large abundances of the $\mathrm{Pb}\left(\mathrm{CH}_{3}\right)_{3}+$ ions of tetramethyllead, trimethylethyllead, and the trimethylbutylleads, the $\mathrm{Pb}\left(\mathrm{CH}_{3}\right)_{2} \mathrm{C}_{2} \mathrm{H}_{5}+$ ion of dimethyldiethyllead, the $\mathrm{Pb}\left(\mathrm{CH}_{3}\right)\left(\mathrm{C}_{2} \mathrm{H}_{5}\right)_{2}+$ ion of methyltriethyllead and the $\mathrm{Pb}\left(\mathrm{C}_{2} \mathrm{H}_{5}\right)_{3}+$ ion of tetraethyllead. Tetrapropyllead and tetra-iso-butyllead are evidently exceptions to this, probably for steric reasons. However, the trimethyl- $n$-butyllead spectrum includes an abundant ion, $\mathrm{PbC}_{6} \mathrm{H}_{15}{ }^{+}$, which very probably has the trialkyl configuration, $\mathrm{Pb}\left(\mathrm{CH}_{3}\right)_{2} \mathrm{C}_{4} \mathrm{H}_{9}$.

Ions heavier than $\mathrm{PbC}_{6} \mathrm{H}_{15}^{+}$are relatively rare. Molecule ions of only five of the lead alkyls were observed with abundances as large as 1 percent of the most abundant ion. This fact complicates the mass spectrometer analysis of mixtures of these compounds, particularly for those containing small amounts of lower molecular weight compounds.

\section{References}

[1] V. H. Dibeler, J. Research NBS 49, 235 (1952) RP2358.

[2] V. H. Dibeler and F. L. Mohler, J. Research NBS 47, 337 (1951) RP2259.

[3] L. Friedman, A. P. Irsa, and G. Wilkinson, J. Am. Chem. Soc. $7 \%, 3689$ (1955).

[4] R. M. Farquhar, G. H. Palmer, and K. L. Aitken, Nature 172, 860 (1953)

[5] V. H. Dibeler, Anal. Chem. 27, 1958 (1955).

[6] R. C. Taylor and W. S. Young, Ind. Eng. Chem., Anal. Ed. 17, 811 (1945)

[7] E. M. Charlet, Consolidated Electrodynamics Corp., Pasadena, Calif., Group Report No. 14 (March 1950).

[8] Catalog of mass spectral data, American Petroleum Institute, Carnegie Institute of Technology, Pittsburgh, Pa. (1952)

Washington, March 15, 1956. 